\title{
Analisis Dampak Sosial, Budaya dan Psikologis Lajang di Indonesia
}

\author{
Dwi Hardani Oktawirawan ${ }^{1 *}$, Ananta Yudiarso \\ Fakultas Psikologi, Universitas Surabaya \\ Jalan Tenggilis Mejoyo Surabaya Jawa Timur \\ *Email: dhoktawirawan@gmail.com
}

Naskah diterima 13 September 2020, Revisi 10 Oktober 2020, Terbit 29 Oktober 2020

\begin{abstract}
Abstrak
DOI: doi.org/10.21107/pamator.v13i2.7872

Jumlah lajang di Indonesia mengalami tren peningkatan dari tahun ke tahun. Tulisan ini bertujuan untuk menganalisis dampak yang ditimbulkan terkait lajang baik dari sudut pandang sosial, budaya, maupun psikologis. Analisis dilakukan secara kualitatif terhadap data statistik kependudukan serta artikel ilmiah terkait lajang di Indonesia yang kemudian hasilnya disajikan dalam bentuk narasi. Lajang di Indonesia mendapatkan berbagai pandangan dari masyarakat baik positif maupun negatif. Seorang lajang dianggap lebih bebas, modern, mandiri, dan berfokus pada karir. Secara negatif lajang juga dianggap kesepian, tidak menarik, dan kurang pandai bersosialisasi. Pandangan negatif serta kurangnya penerimaan membuat lajang merasa tertekan. Secara jangka panjang peningkatan jumlah lajang juga dapat memicu permasalahan baru. Meningkatnya jumlah lajang berpotensi menurunkan angka kelahiran yang kemudian mengakibatkan rendahnya presentase penduduk usia produktif di masa mendatang.
\end{abstract}

Kata Kunci : lajang, analisis dampak sosial, stigma, budaya, kesehatan mental

\begin{abstract}
The number of single in Indonesia experiences an increasing trend from year to year. This paper aims to analyze the impact caused by being single, from a social, cultural, and psychological perspective. The analysis was carried out qualitatively on population statistical data and scientific articles related to singles in Indonesia, and then the results were presented in a narrative. Singles in Indonesia get a variety of views from the community both positive and negative. A single person is considered more free, modern, independent, and career-focused. Negatively single is also considered lonely, unattractive, and not good at socializing. Negative views and lack of acceptance make singles feel depressed. In the long run, the increase in the number of singles can also trigger new problems. The increase in the number of singles can have an impact on declining birth rates which then results in a low percentage of the population of productive age in the future.
\end{abstract}

Keywords: singlehood, social impact analysis, stigma, culture, mental health

\section{PENDAHULUAN}

Lajang adalah sebuah status yang berarti bahwa seseorang baik laki-laki maupun perempuan sedang tidak mempunyai pasangan atau memiliki hubungan romantis bersama orang lain (Cindy, 2016; Noverino, 2015). Terdapat berbagai pandangan masyarakat terhadap lajang baik positif maupun negatif. Secara positif seorang lajang dianggap modern dan pekerja keras (Nanik, Tairas, \& Hendriani, 2018). Tidak adanya pasangan juga membuat seseorang dianggap lebih bebas dan mandiri (Septiana \& Syafiq, 2013).
Pada sisi lain lajang juga dipandang sebagai seorang yang tidak laku, kesepian, dan tidak mampu melakukan hubungan sosial dengan baik (Septiana \& Syafiq, 2013; Sudarsono, 2017). Pandangan negatif terhadap lajang secara nyata nampak baik dalam bentuk lelucon, sindiran, dan bahkan penghinaan (Cindy, 2016; Sudarsono, 2017). Diskreditisasi terhadap lajang ini terjadi baik dalam komunikasi langsung maupun melalui media sosial.

Berbagai pandangan yang ada dari masyarakat menjadi masalah tersendiri bagi beberapa orang. Seseorang menjadi tidak nyaman saat mendapatkan berbagai ejekan 
atau penghinaan terkait status lajangnya (Septiana \& Syafiq, 2013). Selain itu pandangan negatif yang ada dapat membuat seorang lajang merasa kesepian karena tidak mendapatkan penerimaan dari orang-orang disekitarnya (Septiana \& Syafiq, 2013). Meskipun demikian, tidak semua lajang merasakan permasalahan yang sama. Survei kebahagiaan yang dilakukan oleh Badan Pusat Statistik (2017) menunjukkan bahwa kelompok masyarakat yang belum pernah menikah mempunyai indeks kebahagiaan tertinggi di antara kelompok lainnya. Hal tersebut menunjukkan bahwa status lajang tidak selalu berkaitan erat dengan dampak negatif.

Data menunjukkan bahwa terdapat tren peningkatan jumlah lajang di Indonesia. Pada tahun 2000 jumlah perempuan lajang di rentang usia 35-39 tahun berada pada angka 3,5 \% (Himawan, Bambling, \& Edirippulige, 2017). Dekade selanjutnya pada tahun 2010 terjadi peningkatan dimana terdapat $3,8 \%$ perempuan dalam rentang usia 35-39 tahun yang berstatus belum pernah menikah (Badan Pusat Statistik, 2010). Hal tersebut menunjukkan bahwa semakin banyak orang yang menunda waktu pernikahan atau bahkan memilih untuk tidak menikah.

Peningkatan jumlah lajang yang terjadi di Indonesia tidak terlepas dari berbagai dampak yang mengiringinya. Artikel ini bermaksud untuk menganalisis dampak yang muncul terkait lajang di Indonesia baik dalam aspek sosial, budaya, maupun psikologis. Analisis ini diharapkan dapat menjadi referensi untuk penelitian selanjutnya maupun aplikasi terapan. Terutama sebagai acuan dalam pembuatan intervensi atau upaya preventif terkait dengan berbagai dampak yang ada.

\section{METODOLOGI}

Metode yang digunakan dalam artikel ini adalah existing statistic yaitu analisis terhadap data statistik atau dokumen yang sudah ada (Neuman, 2017). Data sekunder yang digunakan antara lain data statistik kependudukan dari lembaga terpercaya dan artikel ilmiah yang mencakup hasil penelitian kualitatif, kuantitatif, serta kajian literatur. Data yang dimaksud terkait dengan dampak lajang di Indonesia dalam aspek sosial, budaya, dan psikologis yang diterbitkan dalam waktu 10 (sepuluh) tahun terakhir. Analisis dilakukan secara kualitatif dengan mengelompokkan dampak positif dan negatif dalam ranah penerimaan sosial, perubahan budaya, dan kesehatan mental terkait lajang di Indonesia. Selanjutnya hasil analisis dari setiap aspek disajikan secara kualitatif dalam bentuk narasi.

Tabel 1. Metode Analisis

\begin{tabular}{lcc}
\hline \multicolumn{1}{c}{ Fokus } & Data & Analisis \\
\hline Sosial & Stigma & Penerimaan sosial \\
Psikologis & Well being & Kesehatan mental \\
Budaya & $\begin{array}{c}\text { Tren usia } \\
\text { pernikahan }\end{array}$ & Perubahan budaya \\
& & \\
\hline
\end{tabular}

\section{HASIL DAN PEMBAHASAN}

Menjadi lajang memang tidak terlepas dari berbagai pandangan masyarakat baik itu positif maupun negatif. Secara negatif lajang dianggap tidak laku dan kurang mampu menjalin hubungan sosial dengan baik (Septiana \& Syafiq, 2013). Selain itu seorang lajang juga mendapatkan label seperti perawan tua, dianggap kesepian, tidak percaya diri, jual mahal, dan sombong (Nanik et al., 2018). Lajang memang tidak terlepas dari berbagai stigma negatif antara lain dianggap tidak bahagia, tidak puas dengan hidup, dan tidak menarik (Depaulo \& Morris, 2006; Greitemeyer, 2009).

Menjadi seseorang berstatus lajang merupakan sebuah masalah bagi beberapa orang. Tekanan terhadap lajang semakin kuat di Indonesia mengingat karakter budaya Indonesia yang tergolong budaya kolektif (Sumintardja, Rismiyati, Sodjakusumah, Moeliono, \& Fitriana, 2001). Nilai atau norma dalam masyarakat memegang peranan penting dalam berbagai hal termasuk pengambilan keputusan. Seseorang akan berupaya melakukan hal yang sesuai dengan nilai masyarakat sehingga secara sosial dapat diterima (Gea, 2010). Adanya nilai dalam masyarakat Indonesia yang menyatakan bahwa seseorang harus menikah dan memiliki anak di usia tertentu membuat beberapa orang merasa tertekan. Tekanan tersebut bisa muncul karena seseorang memiliki nilai yang sama dengan nilai masyarakat mayoritas namun sulit dalam menemukan pasangan. 
Tabel 2. Hasil Analisis

\begin{tabular}{|c|c|c|}
\hline Fokus & Dampak Positif & Dampak Negatif \\
\hline Sosial & $\begin{array}{l}\text { - Seorang lajang dianggap mandiri, bebas, } \\
\text { sukses, pekerja keras, tangguh, modern, } \\
\text { berfokus pada karir dan bisa menikmati } \\
\text { hidup (Nanik et al., 2018). }\end{array}$ & $\begin{array}{l}\text { - Mendapat stigma dari masyarakat dimana lajang } \\
\text { menerima berbagai labeling, dianggap } \\
\text { berorientasi diri sendiri, jual mahal, pemilih, } \\
\text { emosional, kesepian, sombong, dan kekanak- } \\
\text { kanakan (Nanik et al., 2018). } \\
\text { - Mendapatkan tekanan untuk segera menikah } \\
\text { atau berpasangan. Dianggap kurang mampu } \\
\text { bersosial, tidak laku, dan menutup diri (Septiana } \\
\text { \& Syafiq, 2013). } \\
\text { - Mendapatkan stereotip seperti terlalu pemilih } \\
\text { dan dituduh homoseksual (Himawan, Bambling, } \\
\text { \& Edirippulige, 2018). }\end{array}$ \\
\hline Psikologis & $\begin{array}{l}\text { - Penelitian oleh Nanik, Putri, \& Hariani } \\
\text { (2016) menunjukkan bahwa tidak } \\
\text { terdapat perbedaan psychological well } \\
\text { being antara orang yang sudah menikah } \\
\text { dengan orang yang belum menikah baik } \\
\text { pada laki-laki ( } \mathrm{p}=0,313, \mathrm{p}>0.05 \text { ) maupun } \\
\text { pada perempuan ( } \mathrm{p}=0.139, \mathrm{p}>0.05 \text { ). } \\
\text { - Seorang wanita lajang tetap mampu } \\
\text { mencapai psychological well being dalam } \\
\text { kehidupannya (D.W.S, 2018). } \\
\text { - Pada tahun } 2014 \text { dan } 2017 \text { indeks } \\
\text { kebahagiaan lajang lebih tinggi daripada } \\
\text { orang yang sudah menikah yaitu pada } \\
\text { angka 68,77 dan } 71,53 \text { (Badan Pusat } \\
\text { Statistik, 2017). }\end{array}$ & $\begin{array}{l}\text { - Merasa tertekan karena mendapatkan berbagai } \\
\text { stigma dan merasa kesepian bukan karena tidak } \\
\text { mempunyai pasangan namun karena adanya } \\
\text { stigma serta tekanan (Septiana \& Syafiq, 2013). } \\
\text { - Kurang bahagia karena tidak mendapatkan } \\
\text { penerimaan dari orang terdekat seperti keluarga } \\
\text { terkait status lajangnya (Himawan et al., 2018). }\end{array}$ \\
\hline Budaya & $\begin{array}{l}\text { - Bergesernya pandangan dimana } \\
\text { pernikahan tidak lagi dianggap sebagai } \\
\text { jalur utama untuk mendapatkan } \\
\text { kebahagiaan karena lajang juga bisa } \\
\text { bahagia bahkan lebih bahagia dari orang } \\
\text { menikah (Himawan et al., 2017). }\end{array}$ & $\begin{array}{l}\text { - Terdapat peningkatan tren usia pernikahan } \\
\text { pertama di Indonesia dimana pada } 2016 \\
\text { menjadi } 27,5 \text { tahun untuk laki-laki (Lembaga } \\
\text { Demografi, 2017). } \\
\text { - Median usia kawin pertama pada perempuan di } \\
\text { Indonesia meningkat dari 20,1 pada tahun } 2012 \\
\text { menjadi 21,8 pada tahun 2017 (Badan Pusat } \\
\text { Statistik, 2018). }\end{array}$ \\
\hline
\end{tabular}

Stigma negatif dan tekanan yang ada tentu memberikan dampak bagi seorang lajang. Seseorang yang tidak mempunyai pasangan akan merasa tertekan karena mendapat ejekan atau paksaan untuk segera mendapatkan pasangan (Septiana \& Syafiq, 2013). Seorang lajang juga bisa menjadi merasa kesepian bukan karena tidak mempunyai pasangan namun karena orang-orang di sekitarnya justru memberikan tekanan terkait status lajangnya (Septiana \& Syafiq, 2013). Penerimaan dari lingkungan seperti keluarga, saudara, dan teman memegang peranan penting dalam kebahagiaan seseorang (Himawan et al., 2018).

Kondisi yang penuh dengan tekanan juga kemudian dapat menimbulkan adanya pengambilan keputusan yang tergesa-gesa untuk segera mendapatkan pasangan dan menikah (Spielmann et al., 2013). Pernikahan yang dilakukan tanpa pertimbangan matang dalam kasus ini biasanya hanya berfokus pada pemenuhan standar sosial. Seseorang menikah hanya untuk segera memiliki pasangan tanpa memperhatikan apakah kualitas hubungan yang dijalin benar-benar harmonis atau tidak (Spielmann et al., 2013). Hal ini mampu menjadi potensi terciptanya keluarga yang tidak harmonis di masa mendatang.

Pada sudut pandang yang lain, secara positif lajang dianggap sebagai orang yang mandiri, menikmati hidup, tangguh, dan berfokus pada karir atau pendidikan (Nanik et al., 2018). Terlepas dari tekanan yang ada, lajang sebenarnya mempunyai indeks kebahagiaan tertinggi jika dibandingkan dengan orang yang sudah menikah (Badan Pusat Statistik, 2017). Hal tersebut dibuktikan juga dalam penelitian yang dilaksanakan oleh Nanik et al., (2016) yang menunjukkan bahwa tidak terdapat perbedaan kesejahteraan psikologis ketika dilihat dari status perkawinan seseorang. Seseorang yang sedang berstatus lajang 
mampu mencapai kesejahteraan psikologis seperti orang lainnya termasuk seperti orang lain yang memiliki pasangan atau sudah menikah. Sumber kebahagiaan atau kesejahteraan memang tidak hanya bergantung pada kondisi hubungan romantis saja (Greitemeyer, 2009). Hal tersebut kemudian memunculkan pandangan baru bahwa pernikahan bukanlah syarat mutlak bagi seseorang untuk memperoleh kebahagiaan (Himawan et al., 2017).

Pandangan baru terkait lajang di Indonesia juga nampak pada meningkatnya tren usia pertama pernikahan (Lembaga Demografi, 2017). Peningkatan usia pertama pernikahan juga merupakan dampak dari adanya perubahan budaya dimana saat ini setiap orang berhak mengenyam pendidikan tinggi tanpa memandang gender (Himawan et al., 2017). Peluang kebebasan dalam pencapaian karir membuat orang-orang berfokus untuk mematangkan diri baik dalam hal pendidikan maupun pekerjaan.

Peningkatan usia pertama pernikahan yang terus menerus juga dapat menimbulkan permasalahan baru di masa mendatang. Permasalahan yang dimaksud saat ini sudah nampak terjadi di Jepang. Semakin banyak orang Jepang yang memutuskan untuk menunda pernikahan atau bahkan tidak menikah karena berbagai alasan (Endo, 2019). Kondisi tersebut berdampak pada semakin menurunnya angka kelahiran serta jumlah populasi penduduk Jepang (Armandhanu, 2017). Penurunan angka kelahiran tersebut pada waktu yang lama akan berakibat pada ketidakseimbangan generasi dalam sebuah populasi yang dapat mempengaruhi kondisi ekonomi negara (Sebayang, 2019).

\section{KESIMPULAN}

Fenomena lajang yang terjadi di Indonesia tidak terlepas dari berbagai dampak yang ditimbulkannya. Secara positif lajang dianggap lebih bebas dan mandiri dalam menjalani kehidupannya. Menjadi seorang lajang juga tetap membuat seseorang mampu untuk mendapatkan kesejahteraan atau kebahagiaan. Hal tersebut memunculkan pandangan baru bahwa pernikahan bukanlah jaminan bagi seseorang untuk mencapai kebahagiaan. Meskipun demikian peningkatan jumlah lajang juga dapat memicu permasalahan di kemudian hari. Peningkatan jumlah lajang dalam jangka panjang dapat berdampak pada penurunan angka kelahiran yang diikuti oleh rendahnya presentase generasi produktif di masa selanjutnya. Selain itu lajang juga masih mendapatkan berbagai stigma negatif dari masyarakat seperti dianggap kesepian, tidak menarik, dan kurang mampu bersosial. Hal tersebut berakibat pada lajang yang kemudian merasa tertekan karena tidak mendapatkan penerimaan dari lingkungan sekitarnya.

\section{DAFTAR PUSTAKA}

Armandhanu, D. 2017. Sensus: Jomblo di Jepang semakin tua dan bertambah. Kumparan. Retrieved from https://kumparan.com/kumparannews/s ensus-jomblo-di-jepang-semakin-tuadan-bertambah/full

Badan Pusat Statistik. 2010. Penduduk Berumur 10 Tahun Keatas Menurut Kelompok Umur dan Status Perkawinan. Retrieved from https://sp2010.bps.go.id/index.php/site/t abel?tid=271\& $\mathrm{wid}=0$

Badan Pusat Statistik. 2017. Indeks Kebahagiaan Menurut Status Perkawinan, 2013-2017. Retrieved from https://www.bps.go.id/dynamictable/201 7/05/04/1247/indeks-kebahagiaanmenurut-status-perkawinan-20132017.html

Badan Pusat Statistik. 2018. Median Usia Kawin Pertama Perempuan Pernah Kawin Umur 25-49 Tahun Menurut Provinsi 2012 dan 2017. Retrieved from https://www.bps.go.id/dynamictable/201 8/06/06/1445/median-usia-kawinpertama-perempuan-pernah-kawinumur-25-49-tahun-menurut-provinsi2012.html

Cindy, N. 2016. Representasi Meme Jomblo dalam Situs Jejaring Sosial Twitter (Analisis Semiotika Roland Barthes). Jurnal Online Mahasiswa (JOM) Bidang IImu Sosial Dan IImu Politik. Vol 3 (2), 1-14 pp.

Depaulo, B. M., \& Morris, W. L. 2006. The Unrecognized Stereotyping and Discrimination Against Singles. Current 
Directions in Psychological Science. $\begin{array}{llll}\text { Vol } 155 & \text { (5). 251-254 pp. }\end{array}$ https://doi.org/10.1111/j.1467-

8721.2006.00446.x

Endo, K. 2019. Singlehood In 'Precarious Japan': Examining New Gender Tropes And Inter-Gender Communication in $A$ Culture of Uncertainty. Japan Forum. $\begin{array}{llll}\text { Vol } 31 & \text { (2). } 165-186 & \text { pp. }\end{array}$ https://doi.org/10.1080/09555803.2018. 1441167

Gea, A. A. 2010. Pengembangan Culture, Self, and Personality dalam Diri Manusia. Humaniora. Vol 1(1). 37-48 pp.

https://doi.org/10.21512/humaniora.v1i1 .2146

Greitemeyer, T. 2009. Stereotypes of singles: Are singles what we think? European Journal of Social Psychology, Vol $39 . \quad 368-383$ pp. https://doi.org/10.1002/ejsp

Himawan, K. K., Bambling, M., \& Edirippulige, S. 2017. Modernization and Singlehood in Indonesia: Psychological And Social Impacts. Kasetsart Journal of Social Sciences, 1-8

$\mathrm{pp}$. https://doi.org/10.1016/j.kjss.2017.09.0 08

Himawan, K. K., Bambling, M., \& Edirippulige, S. 2018. What Does It Mean To Be Single in Indonesia? Religiosity, Social Stigma, And Marital Status Among Never-Married Indonesian Adults. SAGE Open, 8(3), 1-9.

https://doi.org/10.1177/2158244018803 132

Lembaga Demografi. 2017. Tren usia perkawinan pertama di Indonesia. Retrieved from https://ldfebui.org/wpcontent/uploads/2018/01/BN-112017.pdf

Nanik, Putri, A. L., \& Hariani, L. A. S. 2016. Psychological Well Being Pria dan Wanita Ditinjau Dari Status Pernikahan. Temu IImiah Nasional HIMPSI, 1-9.
Nanik, Tairas, M. M. W., \& Hendriani, W. (2018). "She Is a Spinster": A Descriptive Study on Perception Toward Single Women. International Journal of Engineering \& Technology Vol $\quad 7 \quad 1-9 \quad$ pp. https://doi.org/10.14419/ijet.v7i2.29.139 95

Neuman, W. L. 2017. Metodologi Penelitian Sosial: Pendekatan Kualitatif Dan Kuantitatif (7th ed.). Jakarta: Indeks.

Noverino, R. 2015. Kajian Analisis Wacana Kritis Intertekstualitas pada Terjemahan yang Menggunakan Bahasa Gaul. Prosiding PESAT6. 108$116 \mathrm{pp}$.

Sebayang, R. 2019). Banyak Jomblo, Ekonomi Jepang Jadi Loyo. CNBC Indonesia. Retrieved from https://www.cnbcindonesia.com/lifestyle /20191206164317-33-121046/banyakjomblo-ekonomi-jepang-jadi-loyo

Septiana, E., \& Syafiq, M. 2013. Identitas“ Lajang" (Single Identity) dan Stigma: Studi Fenomenologi Perempuan Lajang Di Surabaya. Jurnal Psikologi Teori \& Terapan. Vol 4(1). 71-86 pp. http://dx.doi.org/10.26740/jptt.v4n1.p7186

Spielmann, S. S., MacDonald, G., Maxwell, J. A., Joel, S., Peragine, D., Muise, A., \& Impett, E. A. 2013. Settling for Less Out of Fear Of Being Single. Journal of Personality and Social Psychology. Vol 105 (6). 1049-1073 pp. https://doi.org/10.1037/a0034628

Sudarsono, S. C. 2017. Diskreditisasi dan Resistansi Jomblo yang Terepresentasi dalam Wacana Meme Humor. Prosiding SETALI 2017. 415-419 pp.

Sumintardja, E. N., Rismiyati, E. K., Sodjakusumah, T., Moeliono, M. F., \& Fitriana, E. (2001). Studi tentang Faktor Determinan Pembentuk Kepribadian Manusia Indonesia yang Mencerminkan Perilaku Sehat Mental Dalam Tatanan Budaya Kolektif. Jurnal Sosiohumaniora. Vol 3 (1). 13-25 pp. 
200 Jurnal Pamator 